\title{
Dental pain, use of dental services and oral health-related quality of life in southern Brazil
}

\section{Charles Henrique CAVALHEIRO(a) Claides ABEGG(b) Victor Nascimento FONTANIVE(c) Rosane Silvia DAVOGLIO(d)}

\footnotetext{
(a) Universidade Federal de Santa Maria - UFSM, Center of Health Sciences, Postgraduate Program in Dental Sciences, Santa Maria, RS, Brazil.

(b) Universidade Federal do Rio Grande do Sul - UFRGS, School of Dentistry, Department of Preventive and Social Dentistry, Porto Alegre, RS, Brazil.

(c)Grupo Hospitalar Conceição, Serviço de Saúde Comunitária, Porto Alegre, RS, Brazil.

(d) Universidade Federal do Vale do São Francisco - UNIVASF, School of Nursing, Petrolina, PE, Brazil.
}

Declaration of Interests: The authors certify that they have no commercial or associative interest that represents a conflict of interest in connection with the manuscript.

\section{Corresponding Author:}

Claides Abegg

E-mail: claides.abegg@gmail.com

DOI: 10.1590/1807-3107BOR-2016.vol30.0039

Submitted: May 20, 2015

Accepted for publication: Nov 12, 2015

Last revision: Dec 08, 2015

\begin{abstract}
This study aimed at assessing the relationship between dental pain and the reason for using dental services and oral health quality of life in people aged 50 to 74 years in southern Brazil. A cross-sectional population-based study was conducted with 720 individuals aged 50 to 74 years, living in three health districts in the city of Porto Alegre. Dental impacts on daily life and sociodemographic data were assessed using structured interviews. The Oral Impacts on Daily Performance - OIDP instrument was used to measure oral impacts. The information was analyzed by Poisson regression with robust variance adjustment, taking into account cluster sampling. Dental pain was present in $32.5 \%$ of those reporting an oral impact on their daily activities. Dental pain most frequently affected talking (37.6\%), cleaning teeth and gums (37.0\%) and enjoying the companionship of people $(36.5 \%)$. After adjustments to the multivariate analysis, the reason for dental visits due to dental pain was found to have a high impact on daily activities [RP 1.68 (1.11 - 2.54].
\end{abstract}

Keywords: Oral Health; Pain; Prevalence; Quality of Life.

\section{Introduction}

There is an association between dental pain and discomfort, loss of working hours and impairment of social functions. ${ }^{1,2}$ Pain is a common symptom or subjective expression of the oral condition of individuals, and may affect daily activities. ${ }^{3,4}$ It is reported as a major cause of psychosocial, physical and economic impact. ${ }^{5,6}$ Talking, eating, and cleaning teeth are the daily activities most often affected by pain,, 7 although difficulties in sleeping, socializing and working have also been mentioned. ${ }^{5,6}$ Dental pain is the most common ${ }^{4,8,9}$ orofacial pain; its estimated prevalence ranges from $7 \%$ to $66 \%$, affecting $11 \%$ of adults aged 50 to 59 years. ${ }^{10}$ Dental pain is one of the main reasons for visiting the dentist. ${ }^{11,12,13}$ This is not surprising, because dental pain is the main cause of impairment of most daily activities, ${ }^{3}$ influencing the use of dental services ${ }^{11}$ and affecting the quality of life of individuals. ${ }^{6,14}$

Peoples' perceptions of their oral health status and the related impacts of dental pain on their daily lives are important in planning services designed to improve the quality of life of individuals. Therefore, a study was planned and conducted on a representative sample of adults and elderly individuals living in three health districts of a large Brazilian 
city. Its objectives were to assess the relationship between use of dental services and levels of oral health quality of life related to dental pain, as well as to investigate how dental pain influences the performance of daily activities in people aged 50 to 74 years in southern Brazil.

\section{Methodology}

A population-based cross-sectional study was carried out in Porto Alegre, the main city of Rio Grande do Sul State, Brazil. Porto Alegre has 82 districts, grouped into 16 Health Districts. Three of these were randomly selected: Partenon, Glória and Leste. The target population comprised residents aged 50 to 74 years, living in these three health districts.

Before carrying out the main study, a pilot study was conducted on 40 adults and elderly individuals to train and calibrate interviewers, and test the adequacy of the instruments. This research is part of a larger study, whose sample calculation was performed by estimating a prevalence of 0.50 for the outcome, a confidence interval of $95 \%$ and a sampling error of $4 \%$. A sample size of 601 subjects was needed. A further $10 \%$ were added in case of non-response. Because the study was dealing with a multistage sampling, a design-effect of $20 \%$ was applied, yielding a final sample of 793 subjects.

Participants were selected by multistage proportional random sampling. Three of the 16 health districts of Porto Alegre were randomly selected. Then, 98 census sectors were randomly chosen from the selected districts, through listings and maps obtained from the Municipal Health Department of Porto Alegre. The number of subjects interviewed in the health districts was proportional to the total number of people living in each district. Only one person from each household was interviewed. Visitors and people not normally living in the household were excluded.

A questionnaire was administered for the purpose of collecting data on sociodental indicators, demographic factors and use of health services. It was composed of questions on socioeconomic status, use of dental services and dental pain in the last six months. Dental pain was measured using a single question adapted from an earlier study entitled
Oral Health Conditions of the Brazilian Population 2002-2003: 15 "How much pain have your teeth and gums caused you in the last six months? No pain; little pain; moderate pain; severe pain".

The impact of dental pain on daily activities was assessed using the Oral Impact on Daily Performance (OIDP) questionnaire. ${ }^{16,17}$ This instrument was cross-culturally adapted to Portuguese, ${ }^{18}$ by using a translation/back-translation method integrated with expert panel reviews. The internal and external reliability was also evaluated.

The Brazilian version of the OIDP is composed of eleven daily activities related to physical, psychological and social factors: (1) eating, (2) speaking, (3) cleaning teeth and gums, (4) performing light physical activities, (5) going out, (6) sleeping, (7) smiling, laughing and showing one's teeth without being ashamed, (8) emotional state, (9) working, (10) enjoying the companionship of people and (11) resting. ${ }^{16,17,18}$ The classification system for OIDP quantifies the impact of daily performance by multiplying frequency (distributed on a scale ranging from 1 to 5 ) by severity (distributed on a scale ranging from 0 to 5 ) for each of the eleven daily activities. The individual index results from the sum of values of the eleven performances. The sum of all individual scores divided by the number of people in a given population yielded the OIDP index for the population. The internal reliability of OIDP was 0.69 (Cronbach's alpha).

In this study, the OIDP outcome was individuals with an OIDP greater than zero. Subjects were divided into tertiles; those with an OIDP of 0 were excluded. The individuals with an OIDP from $>0.0$ to 14.54 were classified as low impact, whereas the group with the highest OIDP values $(>14.55)$ was classified as high impact. The independent variables were sex, age (50-59 years, 60-74 years), education (six years or more, less than 6 years), monthly income (higher than a minimum wage, up to 1 minimum wage), and reason for a dental visit (routine care, maintenance or prevention, treatment for pain or other reasons).

The data were collected by 4 previously trained interviewers and 4 recorders. The data reliability was performed by re-interviewing $5 \%$ of the sample within 7 days. The intraclass coefficients were 0.85 for 
the complementary questions of the questionnaire and 0.80 only for the OIDP.

The data were analyzed using Poisson regression with robust variance adjustment, taking into account a cluster sampling. The Stata 9.0 program (Stata Corp., College Station, USA) and the Svyset commands were used to perform the analysis, after the sampling stages.

The analysis of population representativeness was conducted by comparing the data on sex and age variables, obtained in the survey, with information about the population of selected health districts. ${ }^{19}$ The male population was under-represented in the age group of 50-59 years, whereas the female population was over-represented in the group of 60-74 year olds. The sample was adjusted by the svyset/weight function, assigning differentiated sampling weights to each sample group studied, using the ratio of population $\mathrm{N} /$ sample $\mathrm{n}$.

Initially, a descriptive analysis was undertaken to assess the general characteristics of the sample. The association between dental pain and each of the daily activities investigated was performed using the Pearson's Chi-Square test. The existence of an association between the outcome and the factors studied was verified by means of exploratory univariate analysis. Next, multivariate analysis was performed to adjust for the sociodemographic variables.

The present study is part of the research entitled "Assessment of the Dental Impact on Daily Performance of Individuals aged 50-74 years in Porto Alegre, RS", approved by the Research Ethics Committee of the School of Dentistry, Universidade Federal do Rio Grande do Sul - UFRGS, on January 1,2006 , entered under no.6.1 of the minutes, and process no.46/05, following the recommendations of Resolution no.196/96 of the National Health Board (Conselho Nacional de Saúde - CNS). All study participants signed an Informed Consent Form to participate in the study.

\section{Results}

Of the 793 adults and elderly individuals contacted, 720 were interviewed, a response rate of $91 \%$. The majority (416) were women; $53.1 \%$ were aged 50 to 59 years; $68.1 \%$ (490) reported having a personal monthly income of over one minimum wage ( $\mathrm{R} \$ 415.00)$.
Among the individuals studied, $37.9 \%$ had up to five years of schooling.

Dental pain was reported by $32.5 \%$ of those reporting an oral impact on their daily activities. Dental pain most frequently affected talking (37.6\%), cleaning teeth and gums (37.0\%) and enjoying the companionship of people (36.5\%) (Table 1). As regards the use of dental services, $24 \%$ used dental services in the last year because of dental pain, 31.9\% for maintenance and/or prevention, and $43.7 \%$ for other reasons.

Impacts on daily activities related to oral health problems in the last six months were reported by 416 (57.8\%) study individuals; $34.8 \%$ (250) had low OIDP and $17.6 \%$ (127) had high OIDP scores. Univariate analysis found no statistically significant association between sociodemographic variables, such as age, sex, education and income, and high oral impacts (Table 2). High impact (>14.55) was significantly associated with the variable 'reason for a dental visit', where visiting a dentist for reason of pain was the associated category. After adjustments to the multivariate analysis, the reason for a dental visit remained associated with the high impact outcome variable. The reason for dental visits due to dental pain increased the prevalence of individuals reporting high impact by $68 \%$ (95\%CI $1.11-2.54, p=0.014$ ), in relation to those who sought routine, maintenance or preventive care (Table 2).

Table 1. Prevalence of dental pain and daily performance affected by dental pain in Brazilian adults and elderly individuals.

\begin{tabular}{lcc}
\hline $\begin{array}{l}\text { Performance/Daily } \\
\text { activities }\end{array}$ & $\begin{array}{c}\text { Prevalence of the } \\
\text { impact } \\
\mathrm{n}(\%)\end{array}$ & $\begin{array}{c}\text { Individuals with } \\
\text { Dental Pain } \\
\mathrm{n}(\%)\end{array}$ \\
\hline Any impact & $416(57.8)$ & $135(32.5)$ \\
Eating & $265(36.8)$ & $88(32.8)$ \\
Talking & $141(19.6)$ & $53(37.6)$ \\
Cleaning & $92(12.8)$ & $34(37.0)$ \\
Performing light & $11(1.5)$ & $3(27.3)$ \\
physical activities & $221(30.7)$ & $74(33.5)$ \\
Smiling & $66(9.2)$ & $20(29.9)$ \\
Sleeping & $61(8.5)$ & $21(34.4)$ \\
Going out & $99(13.7)$ & $32(32.7)$ \\
Emotional State & $27(13.7)$ & $8(29.6)$ \\
Working & $86(11.9)$ & $31(36.5)$ \\
Enjoying the & $28(3.9)$ & $9(32.1)$ \\
companionship of people & &
\end{tabular}


Table 2. Prevalence ratio (PR) among the explanatory variables. Poisson Regression Model with High Impact (OIDP > 14.55) as the dependent variable and low OIDP (OIDP $>0$ to 14.54) as a reference category.

\begin{tabular}{|c|c|c|c|}
\hline & High Impact n (\%) & Unadjusted Prevalence Ratio $(95 \% \mathrm{Cl})$ & Adjusted Prevalence Ratio $(95 \% \mathrm{Cl})$ \\
\hline Age & $\mathrm{p}^{*}=0.055$ & $\mathrm{p}^{* *}=0.118$ & $\mathrm{p}^{* * *}=0.068$ \\
\hline 50 to 59 years & $78(61.4)$ & 1 & 1 \\
\hline 60 to 74 years & $49(38.6)$ & $0.78(0.58-1.05)$ & $0.75(0.55-1.02)$ \\
\hline Sex & $p^{*}=0.337$ & $p^{* *}=0.792$ & $p^{* * *}=0.316$ \\
\hline Male & $75(59.1)$ & 1 & 1 \\
\hline Female & $52(40.9)$ & $1.04(0.76-1.42)$ & $0.84(0.60-1.17)$ \\
\hline Education & $\mathrm{p}^{*}=0.847$ & $p^{* *}=0.850$ & $p^{* * *}=0.882$ \\
\hline 6 years or more & $78(61.4)$ & 1 & 1 \\
\hline Less than 6 years & $49(38.6)$ & $0.97(0.72-1.32)$ & $1.02(0.74-1.41)$ \\
\hline Income & $p^{*}=0.600$ & $\mathrm{p}^{* *}=0.563$ & $p^{* * *}=0.310$ \\
\hline More than one monthly minimum wage ( $\mathrm{R} \$ 415.00)$ & $89(70.1)$ & 1 & 1 \\
\hline Up to one monthly minimum wage ( $R \$ 415)$ & $38(29.9)$ & $0.90(0.66-1.25)$ & $0.84(0.60-1.17)$ \\
\hline \multirow{2}{*}{ Reasons for Dental Visit } & \multirow{2}{*}{$p^{*}=0.115$} & $\mathrm{p}^{* * 1}=0.028$ & $\mathrm{p}^{* * * 1}=0.014$ \\
\hline & & $\mathrm{p}^{* * 2}=0.336$ & $p^{* * * 2}=0.087$ \\
\hline Routine, maintenance or preventive care & $28(22.2)$ & 1 & 1 \\
\hline Visit for pain reasons & $39(31.0)$ & $1.55(1.04-2.31)$ & $1.68(1.11-2.54)$ \\
\hline${ }^{2}$ Visit for other treatments & $59(46.8)$ & $1.20(0.82-1.76)$ & $1.41(0.95-2.10)$ \\
\hline
\end{tabular}

\section{Discussion}

This study found that visiting the dentist because of pain increased the prevalence of high dental impact on daily activities of individuals by $68 \%$, highlighting the role of dental pain in the oral health-related quality of life of individuals. This was one of the first population-based studies conducted in Brazil, showing the impact of the use of dental services due to pain in the performance of daily activities by individuals aged 50 to 74 .

Research to date has shown that pain influences most dimensions of quality of life, mainly the physical and emotional ones. ${ }^{20}$ A meaningful experience of pain may intervene in the normal functioning of people, and thus have a major effect on their well-being. ${ }^{21}$ Dental pain is one of the main causes of impact on people's daily activities, ${ }^{3}$ and is related to difficulty in eating ${ }^{2,22}$ socialization, ${ }^{4}$ and sleeping, ${ }^{5}$ thus diminishing work productivity $5,6,7$ and emphasizing the need for dental care. ${ }^{11}$

Previous research has shown that dental pain and functional limitation may have a stronger impact on Oral Health Related Quality of Life than clinical conditions. ${ }^{23}$ The main causes of impact found in this population were poorly fitted dentures and missing teeth, confirming that a lay person's evaluation of dental pain may include broader oral impairments than those originated by tooth decay. ${ }^{1,2,24}$

Dental pain is still considered a public health problem and a major reason for seeking dental care. ${ }^{3}$ According to data from the Ministry of Health of Brazil (Ministério da Saúde - MS), dental pain was one of the main reasons for dentist visits in Brazil among different age groups. ${ }^{12}$ A study by Martins et al., ${ }^{25}$ with a representative sample of older Brazilians, demonstrated that tooth and gum pain was one of the main reasons for visiting the dentist in the last year. According to the authors, this finding indicates that people seek dental services only when their oral health status is already poor. In a systematic review conducted on the oral health status of elderly Brazilians and their use of dental services, it was observed that low education and income, as well as insufficient supply of oral health care services, were the main barriers faced by elderly Brazilians to using dental services. ${ }^{26}$ 
Our findings showed that dental pain affected many daily activities. In individuals with pain related impacts, it affected talking, cleaning teeth and gums, eating and enjoying the companionship of people. This result is similar to that of other studies that evaluated adults and the elderly, $3,5,27,28$

Because of its multidimensional nature, pain affects physical, social and psychological well-being. ${ }^{29,30}$ Previous research has shown that dental pain can intervene in the affective domain, increasing moodiness and irritability. ${ }^{23}$ In addition, acute and chronic pain is associated with emotional distress, and can affect family and interpersonal relationships. ${ }^{31}$

Moreover, the ability to eat a variety of foods may promote health benefits, increasing an individual's ability to enjoy the pleasurable sensation of foods and pleasure of participating in meals with others. The improvement in chewing ability per se contributes to ameliorating the OHRQoL of the elderly. ${ }^{32}$

In this study, no significant relationship was found between high impact on daily activities and socioeconomic status of individuals. Similar results were found in an elderly population of Great Britain, ${ }^{17}$ and in elderly Brazilians. ${ }^{5,27}$

The perception of pain may be modulated by individual, social and cultural factors involving past experiences and expectations. Furthermore, each culture or social group has its own way of dealing with pain. Thus the expression of pain may vary according to the cultural norms of each society, in which acceptance or nonacceptance of pain as a normal part of life will determine whether pain will be seen and expressed as a medical/dental issue that requires attention..$^{33}$ Social and cultural norms may therefore have a greater influence than socioeconomic status.

Another possible explanation for this influence, as seen in this study, is the homogeneity in the distribution of years of education and income level of the individuals investigated. Our findings showed no significant difference in high impact on daily activities between the sexes. This result is different from other studies, ${ }^{5,7,17,34}$ but similar to that observed in a former Brazilian study. ${ }^{27}$

The association between sex and oral impact on daily activities is not conclusive in the literature.
Differences in the impact between sexes have been associated with the woman's role in society, based on which women perceive and express their health needs more than men. Biological factors such hormonal changes and a higher prevalence of health conditions that influence a woman's oral health may also account for the differences observed between the sexes. ${ }^{29}$

One of the limitations of this study is that its overall findings represent a 50-to-74-year-old population of the Porto Alegre health districts studied, and cannot be extrapolated to the general population of the same age group of the entire city. Further studies are necessary to fully understand the determinants of dental pain that increase the prevalence of high impact on daily activities, in individuals of this age group.

The findings of this study showed the importance of dental pain in seeking dental services and its high impact on the Oral Health Related Quality of Life of individuals. Thus, oral health services need to be better organized, so that dental pain can become a priority in primary health care in the age range investigated. Data on dental pain can easily be obtained and may be collected by community health workers when visiting the households of subjects. ${ }^{5}$

\section{Conclusion}

It was concluded that the use of dental services was associated to levels of oral health quality of life. Subjects who visited the dentist because of dental pain presented a higher prevalence of dental impact on daily activities, compared with those who visited the dentist for routine, maintenance or preventive care. The daily activities more frequently affected by pain were talking, cleaning teeth and gums and enjoying the companionship of people.

\section{Acknowledgements}

The authors gratefully acknowledge the financial support provided by the Fundação de Amparo à Pesquisa do Estado do Rio Grande do Sul (FAPERGS no.08-04/2006), the Sistema Único de Saúde - SUS and the Conselho Nacional de Desenvolvimento Cientifico e Tecnológico- $\mathrm{CNPq}$, the volunteers and research group. 


\section{References}

1. Macfarlane TV, Blinkhorn AS, Davies RM, Kincey J, WorthingtonHV.Oro-facial painin the community:prevalence and associated impact. Community Dent Oral Epidemiol. 2002;30(1):52-60. doi:10.1034/j.1600-0528.2002.300108.x

2. Petersen PE. The World Oral Health Report 2003. Geneva: World Health Organization; 2003.

3. Adulyanon S, Vourapukjaru J, Sheiham A. Oral impacts affecting daily performance in a low dental disease Thai population. Community Dent Oral Epidemiol. 1996;24(6):385-9. doi:10.1111/j.1600-0528.1996.tb00884.x

4. Locker D, Grushka M. The impact of dental and facial pain. J Dent Res. 1987;66(9):1414-7. doi:10.1177/00220345870660090101

5. Lacerda JT, Ribeiro JD, Ribeiro DM, Traebert J. [Prevalence of orofacial pain and its impact on the oral health-related quality of life of textile industries workers of Laguna, SC, Brazil]. Cienc Saude Colet. 2011;10(16):4275-82. Portuguese. doi:10.1590/S1413-81232011001100033

6. Constante HM, Bastos JL, Peres KG, Peres MA. Socio-demographic and behavioural inequalities in the impact of dental pain among adults: a population-based study. Community Dent Oral Epidemiol. 2012;40(6):498-506. doi:10.1111/j.1600-0528.2012.00701.x

7. Gomes AS, Abegg C. [The impact of oral health on daily performance of municipal waste disposal workers in Porto Alegre, Rio Grande do Sul State, Brazil]. Cad Saude Publica. 2007;23(7):1707-14. Portuguese. doi:10.1590/S0102-311X2007000700023

8. Riley JL 3rd, Gilbert GH, Heft MW. Orofacial pain symptom prevalence: selective sex differences in the elderly? Pain. 1998;76(1-2):97-104. doi:10.1016/S0304-3959(98)00030-X

9. Riley JL 3rd, Gilbert GH. Orofacial pain symptoms: an interaction between age and sex. Pain. 2001;90(3):245-56. doi:10.1016/S0304-3959(00)00408-5

10. Pau AKH, Croucher R, Marcenes W. Prevalence estimates and associated factors for dental pain: a review. Oral Health Prev Dent. 2003;1(3):209-20.

11. Lacerda JT, Simionato EM, Peres KG, Peres MA, Traebert J, Marcenes W. Dental pain as the reason for visiting a dentist in a Brazilian adult population. Rev Saude Publica. 2004;38(3):453-8. doi:10.1590/S0034-89102004000300017

12. Ministério da Saúde (BR). Secretaria de Atenção à Saúde. Departamento de Atenção Básica. Coordenação Nacional de Saúde Bucal. Pesquisa Nacional de Saúde Bucal SB Brasil 2010. Resultados Principais [Internet]. Brasília (DF): Ministério da Saúde; 2011 [cited 2013 Aug 8]. Avaliable from: http://189.28.128.100/dab/docs/geral/projeto_sb2010_ relatorio_final.pdf

13. Lisboa IC, Abegg C. [Oral hygiene habits and use of dental services by adolescents and adults in the Municipality of Canoas, Rio Grande do Sul State, Brazil]. Epidemiol Serv Saude. 2006;15(4):29-39. Portuguese. doi:10.5123/S1679-49742006000400004
14. Slade GD. Epidemiology of dental pain and dental caries among children and adolescents. Community Dent Health. 2001;18(4):219-27.

15. Ministério da Saúde (BR). Secretaria de Atenção à Saúde. Departamento de Atenção Básica. Coordenação Nacional de Saúde Bucal. Projeto SB Brasil 2003. Condições de saúde bucal da população brasileira 2002-2003: resultados principais [Internet]. Brasília (DF): Ministério da Saúde; 2004 [cited 2013 Aug 8]. Available from http://dtr2001.saude.gov.br/editora/ produtos/livros/pdf/05_0053_M.pdf

16. Tsakos G, Marcenes W, Sheiham A. Evaluation of modified version of the index of oral Impacts On Daily Performances (OIDP) in elderly populations in two European countries. Gerodontology. 2001;18(2):121-30. doi:10.1111/j.1741-2358.2001.00121.x

17. Sheiham A, Steele JG, Marcenes W, Tsakos G, Finch S, Walls AW. Prevalence of impacts of dental and oral disorders and their effects on eating among older people; a national survey in Great Britain. Community Dent Oral Epidemiol. 2001;29(3):195-203. doi:10.1034/j.1600-0528.2001.290305.x

18. Abegg C, Fontanive VN, Tsakos G, Davoglio RS, Oliveira MMC. Adapting and testing the oral impacts on daily performances among adults and elderly in Brazil. Gerodontology. 2015;32(1):46-52. doi:10.1111/ger.12051

19. Instituto Brasileiro de Geografia e Estatística. Resultados da amostra do censo demográfico 2000 - malha municipal digital do Brasil: situação em 2001 [Sample results of demographic census 2000 - digital municipal mesh of Brazil: status in 2001]. Rio de Janeiro: IBGE; 2004.

20. Niv D, Kreitler S. Pain and quality of life. Pain Pract. 2001;1(2):150-61. doi:10.1046/j.1533-2500.2001.01016.x

21. Gagliese L, Melzack R. Chronic pain in elderly people. Pain. 1997;70(1):3-14. doi:10.1016/S0304-3959(96)03266-6

22. Petersen PE, Aleksejuniene J, Christensen LB, Eriksen HM, Kalo I. Oral health behavior and attitudes of adults in Lithuania. Acta Odontol Scand. 2000;58(6):243-8. doi:10.1080/00016350050217073

23. Chavers LS, Gilbert GH, Shelton BJ. Two-year incidence of oral disadvantage, a measure of oral health-related quality of life. Community Dent Oral Epidemiol. 2003;31(1):21-9. doi:10.1034/j.1600-0528.2003.00031.x

24. Bittencourt V, Abegg C, Fontanive VN. [Oral health impacts on daily activities of individuals aged 50-74 in three health districts of Porto Alegre/RS]. RFO UPF. 2013;18(1):37-43. Portuguese.

25. Martins AMEBL, Barreto SM, Pordeus IA. [Utilization of dental services among the elderly in Brazil]. Rev Panam Salud Publica. 2007;22(5):308-16. Portuguese. doi:10.1590/S1020-49892007001000003

26. Moreira RS, Nico LS, Tomita NE, Ruiz T. Oral health of Brazilian elderly: a systematic review of epidemiologic status and dental care access. Cad Saude Publica. 2005;21(6):1665-75. Portuguese. doi:10.1590/S0102-311X2005000600013 
27. Pereira KCR, Lacerda JT, Traebert J. The oral impact on daily performances and self-reported quality of life in elderly people in Florianópolis, Brazil. Oral Health Prev Dent. 2009;7(2):163-72.

28. Cohen LA, Bonito AJ, Akin DR, Manski RJ, Macek MD, Edwards RR, et al. Toothache pain: behavioral impact and self-care strategies. Spec Care Dentist. 2009;29(2):85-95. doi:10.1111/j.1754-4505.2008.00068.x

29. Hegarty AM, McGrath C, Hodgson TA, Porter SR. Patient-centred outcome measures in oral medicine: are they valid and reliable? Int J Oral Maxillofac Surg. 2002;31(6):670-74. doi:10.1054/ijom.2002.0260

30. Becker N, Thomsen AB, Olsen AK, Sjøgren P, Bech P, Eriksen J. Pain epidemiology and health related quality of life in chronic non-malignant pain patients referred to a Danish multidisciplinary pain center. Pain. 1997;73(3):393-400. doi:10.1016/S0304-3959(97)00126-7

31. Smith MT, Perlis ML, Smith MS, Giles DE, Carmody TP. Sleep quality and presleep arousal in chronic pain. J Behav Med. 2000 Feb;23(1):1-13. doi:10.1023/A:1005444719169

32. Kim HY, Jang MS, Chung CP, Paik DI, Park YD, Patton LL, et al. Chewing function impacts oral health-related quality of life among institutionalized and community-dwelling Korean elders. Community Dent Oral Epidemiol. 2009;37(5):468-76.

33. Helman CG. Culture, health and illness. 4th ed. London: Hodder Arnold; 2003.

34. McGrath C, Bedi R. Gender variations in the social impact of oral health. J Ir Dent Assoc. 2000;46(3):87-91. 